\title{
First-Principles Study on the Peculiar Water Environment in a Hydrate-Melt Electrolyte
}

Kasumi Miyazaki ${ }^{\dagger}$, Norio Takenaka ${ }^{\dagger}+$, Eriko Watanabe ${ }^{\dagger}$, Shota Iizuka ${ }^{\perp}$, Yuki Yamada ${ }^{\dagger}{ }^{\star}$,

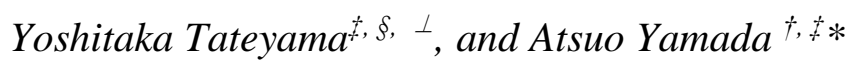

${ }^{\dagger}$ Department of Chemical System Engineering, The University of Tokyo, 7-3-1, Hongo, Bunkyoku, Tokyo 113-8656, Japan

$\$$ Elements Strategy Initiative for Catalysts \& Batteries (ESICB), Kyoto University, 1-30 GoryoOhara, Nishikyo-ku, Kyoto 615-8545, Japan

${ }^{\perp}$ Center for Green Research on Energy and Environmental Materials and International Center for Materials Nanoarchitectonics, National Institute for Materials Science (NIMS), Tsukuba 305-0044, Japan

Corresponding Author

*E-mail: yamada@chemsys.t.u-tokyo.ac.jp (AY) 
1. Radial distribution functions (RDFs) in bulk water

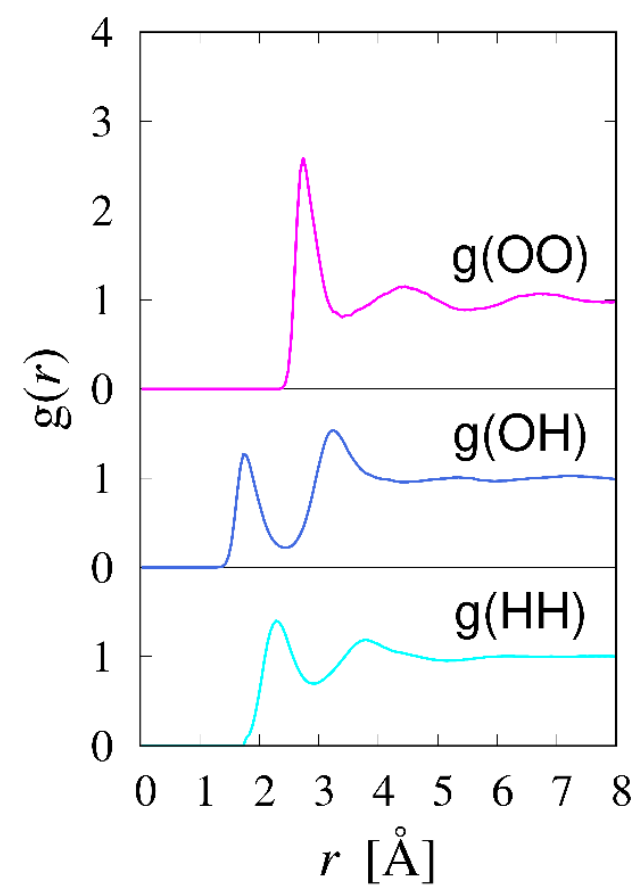

Figure S1. RDFs in bulk water. In each panel, $g(\mathrm{OO}), \mathrm{g}(\mathrm{OH})$, and $\mathrm{g}(\mathrm{HH})$ represent RDFs between $\mathrm{O}$ atoms, between $\mathrm{O}$ atoms and $\mathrm{H}$ atoms, and between $\mathrm{H}$ atoms, respectively. $\mathrm{In} \mathrm{g}(\mathrm{OH})$ and $\mathrm{g}(\mathrm{HH})$, intramolecular pairs are excluded.

\section{Criteria for geometric analysis}

(a) Hydrogen bond

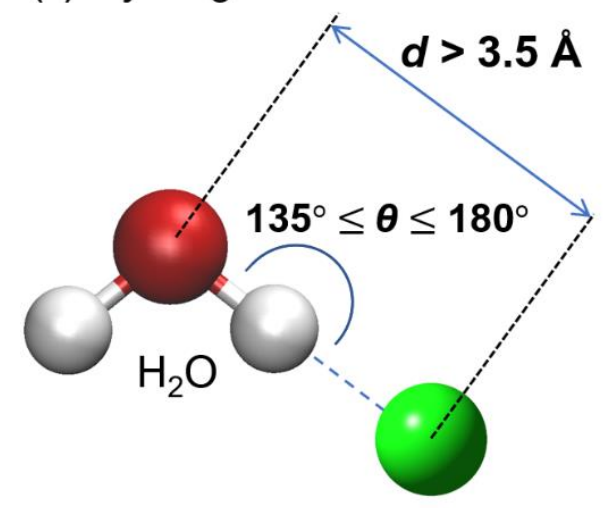

H-bond acceptor (b) $\mathrm{H}_{2} \mathrm{O}-\mathrm{Li}^{+}$coordination

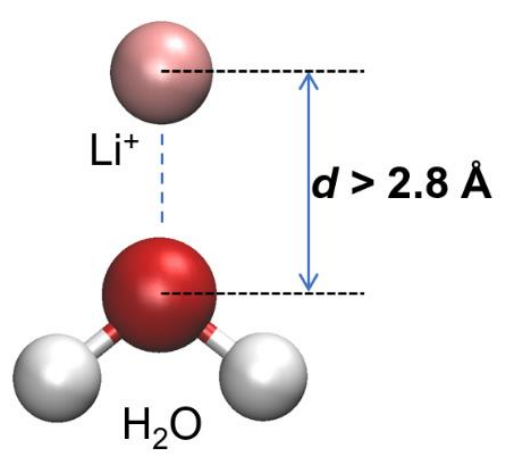

Figure S2. Schematic illustrations of geometric criteria. 


\section{Coordination structure}

(a)

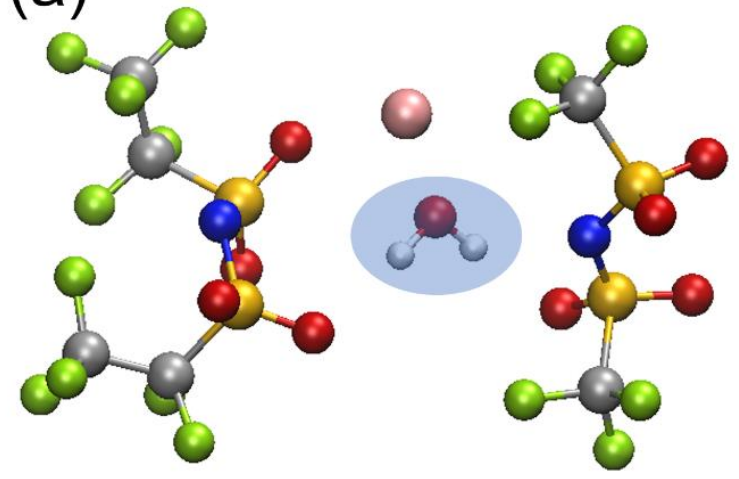

(b)

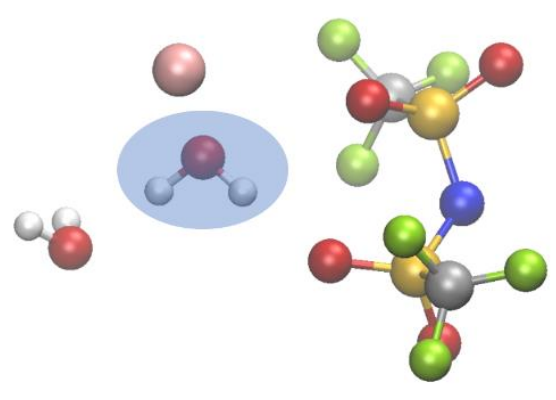

Figure S3. Typical snapshots of $\mathrm{Li}(\mathrm{TFSI})_{0.7}(\mathrm{BETI})_{0.3} \cdot 2 \mathrm{H}_{2} \mathrm{O}$ hydrate melt. (a) $\mathrm{An} \mathrm{H}_{2} \mathrm{O}$ molecule surrounded by only ions (monomer). (b) $\mathrm{An} \mathrm{H}_{2} \mathrm{O}$ molecule surrounded by ions and another $\mathrm{H}_{2} \mathrm{O}$ molecule. 


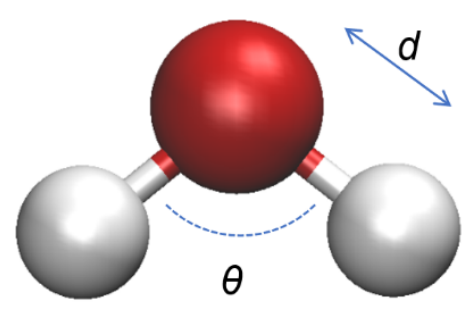

$\Delta d$ : Difference between two $\mathrm{O}-\mathrm{H}$ bond distances in a water molecule

\section{(a) Hydrate melt}

\begin{tabular}{ccc}
\hline$\theta$ & $104.3 \pm 0.05$ & 104.7 \\
$d$ & $0.987 \pm 0.001$ & 0.999 \\
$\Delta d$ & $0.029 \pm 0.002$ & 0.033 \\
\hline
\end{tabular}

Figure S4. Comparison of each parameter for a water molecule between (a) $\mathrm{Li}(\mathrm{TFSI})_{0.7}(\mathrm{BETI})_{0.3} \cdot 2 \mathrm{H}_{2} \mathrm{O}$ hydrate melt and (b) bulk water. The values of (a) are averages of four trajectories.

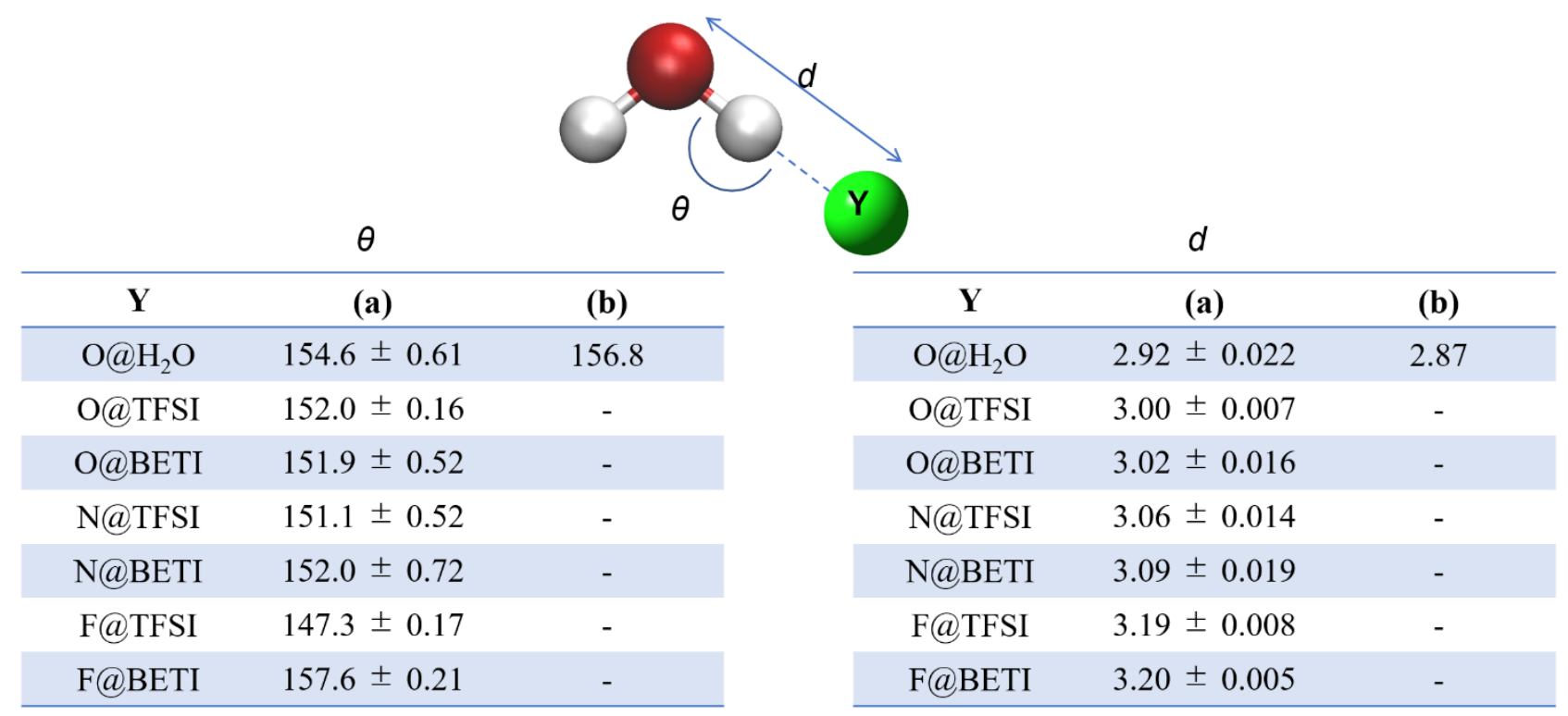

Figure S5. Comparison of each parameter for $\mathrm{H}$-bonds between (a) $\mathrm{Li}(\mathrm{TFSI})_{0.7}(\mathrm{BETI})_{0.3} \cdot 2 \mathrm{H}_{2} \mathrm{O}$ hydrate melt and (b) bulk water. The values of (a) are averages of four trajectories. 


\section{Electronic structure}
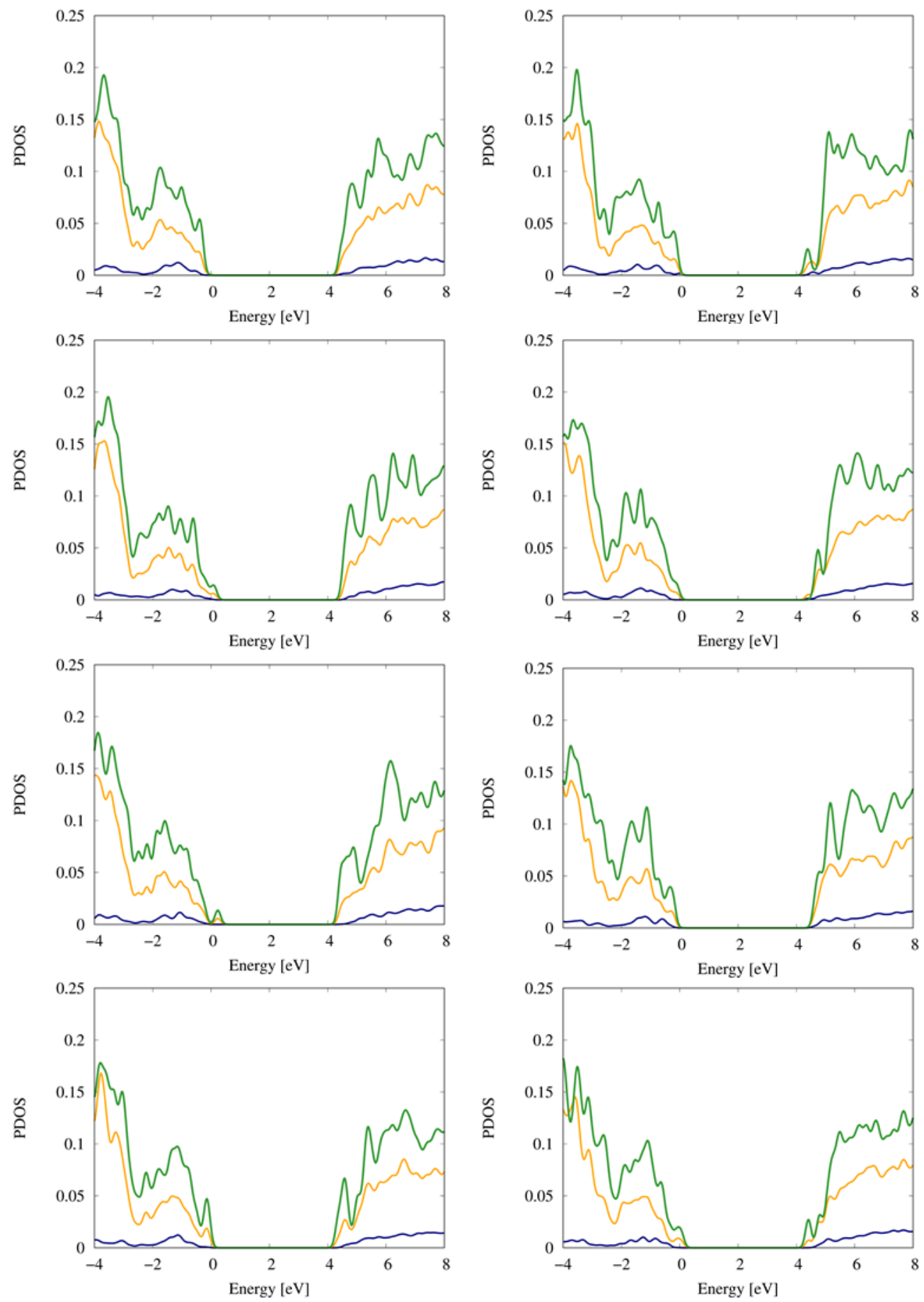

Figure S6. Examples of PDOSs in Li(TFSI $)_{0.7}(\mathrm{BETI})_{0.3} \cdot 2 \mathrm{H}_{2} \mathrm{O}$ hydrate melt. The same as in Figure 7, the navy, orange, and green lines correspond to $\mathrm{H}_{2} \mathrm{O}$, TFSI${ }^{-}$, and $\mathrm{BETI}^{-}$, respectively. Each PDOS is normalized by the number of molecules/ions. 
Table S1. Averaged number of $\mathrm{Li}^{+}$cations contacting each anion in $\mathrm{Li}(\mathrm{TFSI})_{0.7}(\mathrm{BETI})_{0.3} \cdot 2 \mathrm{H}_{2} \mathrm{O}$ hydrate melt. The values are averages of four trajectories.

\begin{tabular}{|c|c|c|}
\hline & TFSI $^{-}$ & BETI $^{-}$ \\
\hline Number of contacting $\mathrm{Li}^{+}$ & $2.1 \pm 0.13$ & $1.9 \pm 0.28$ \\
\hline
\end{tabular}

(a)

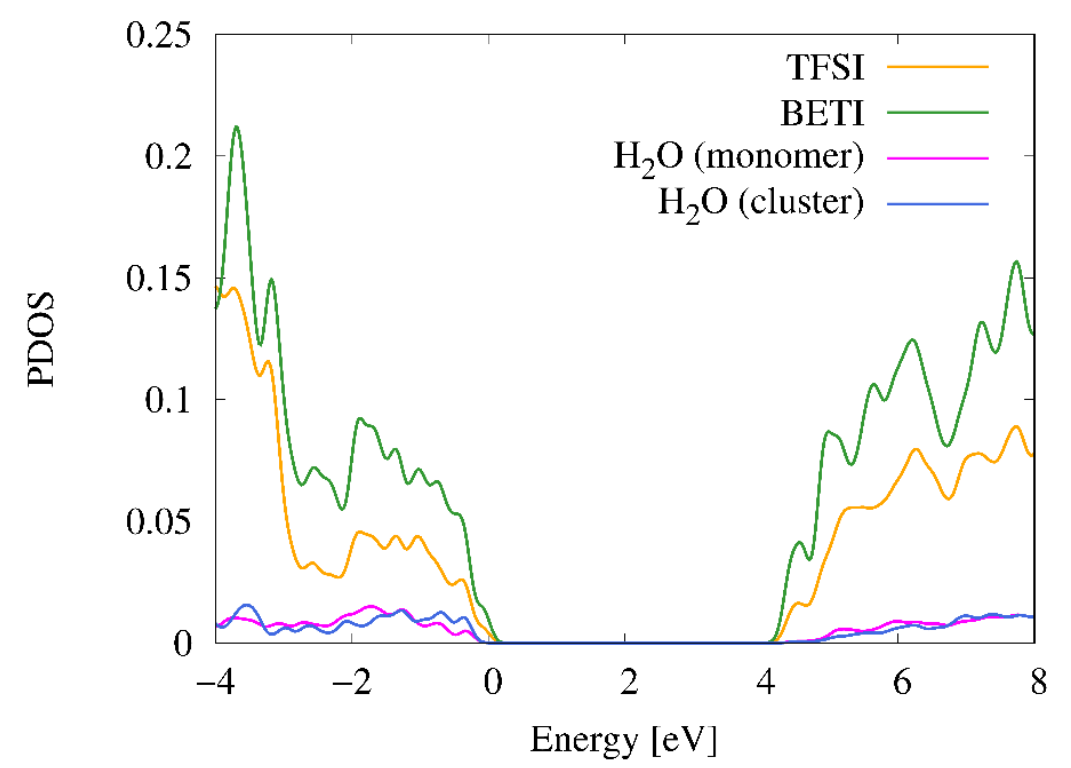

(b)

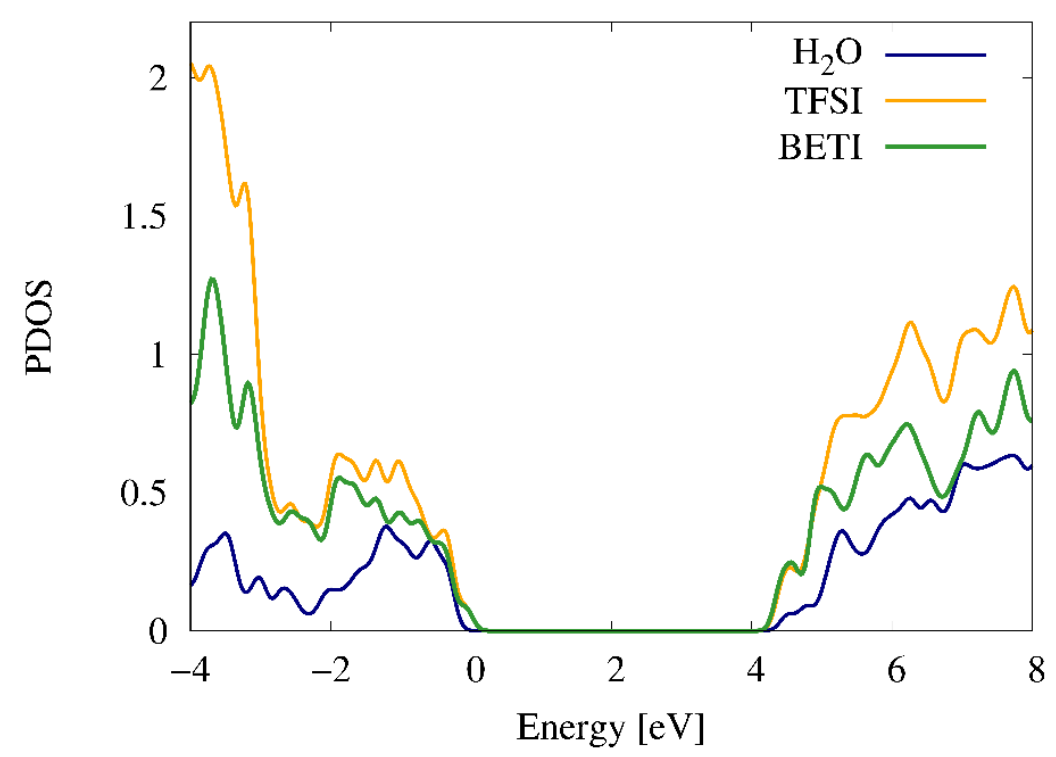

Figure S7. PDOS was calculated from a snapshot identical to Figure 4. (a) $\mathrm{H}_{2} \mathrm{O}$ PDOS divided into monomer and cluster. Each PDOS is normalized by the number of molecules/ions. (b) Unnormalized PDOS which reflects the number of molecules/ions. 


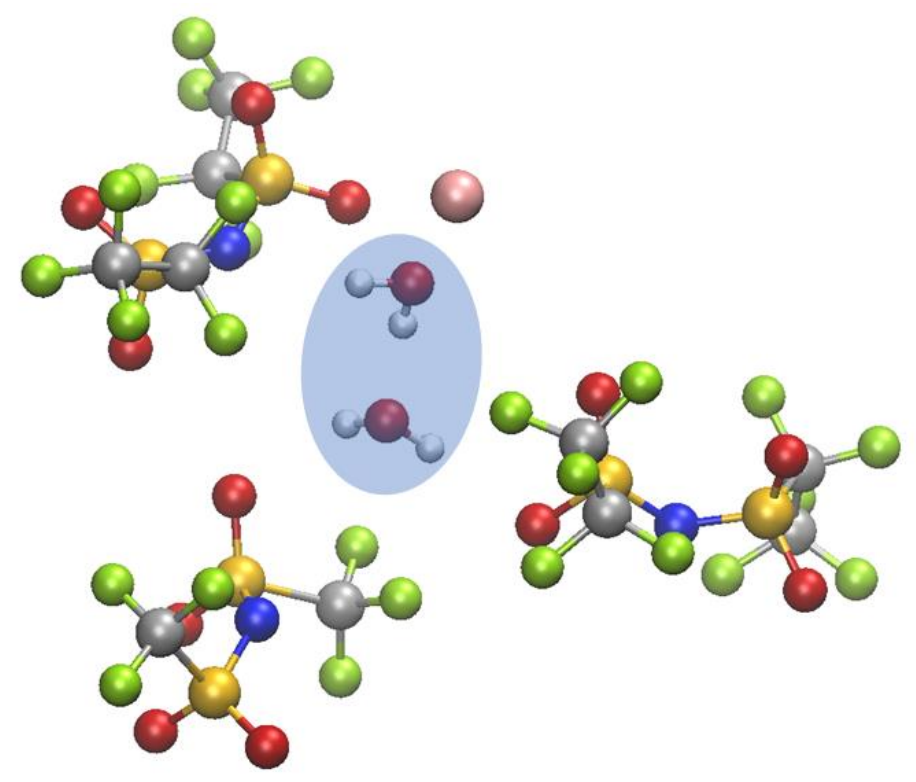

Figure S8. Example of surrounding environment of an $\mathrm{H}_{2} \mathrm{O}$-dimer in $\mathrm{Li}(\mathrm{TFSI})_{0.7}(\mathrm{BETI})_{0.3} \cdot 2 \mathrm{H}_{2} \mathrm{O}$ hydrate melt.

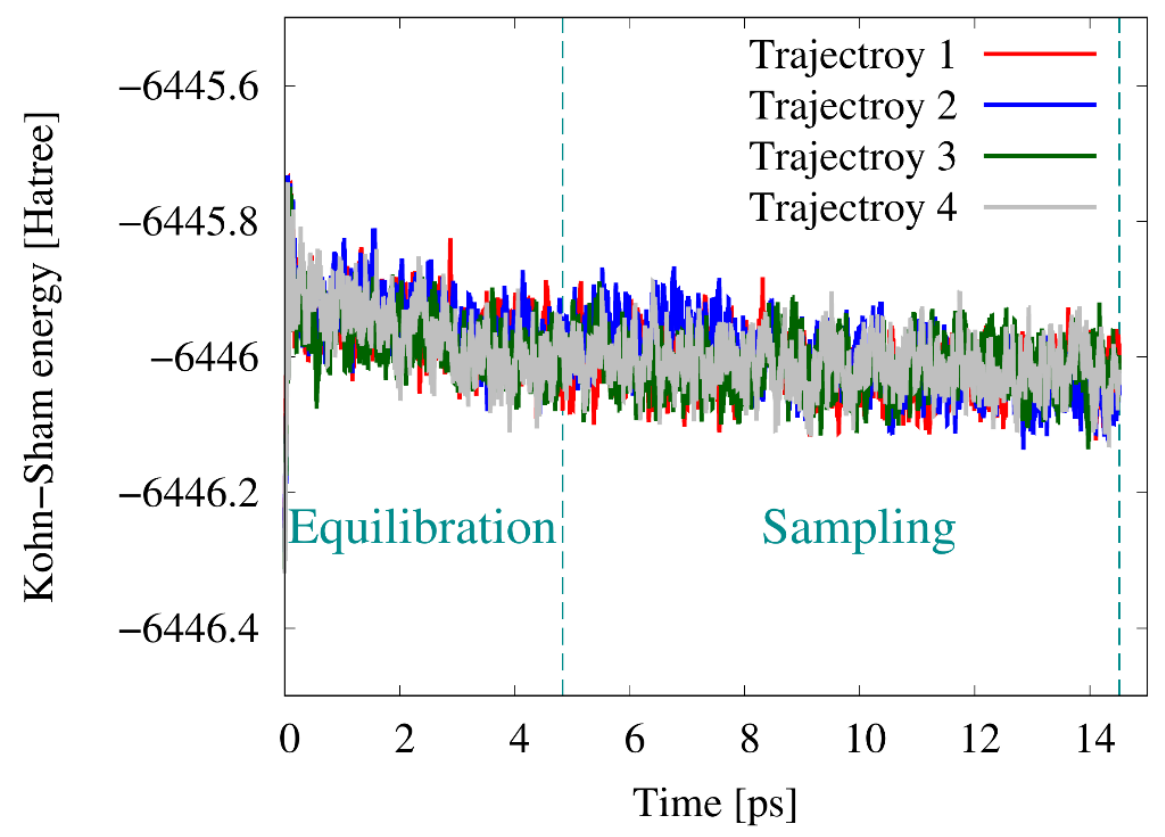

Figure S9. Energy trajectories of four independent CPMD simulations with the Nosé thermostat set to $350 \mathrm{~K}$ in this work. After $4.8 \mathrm{ps}\left(5 \times 10^{4} \mathrm{MD}\right.$ steps $)$ equilibration, we carried out $9.7 \mathrm{ps}\left(10^{5} \mathrm{MD}\right.$ steps $)$ sampling between ca. 4.8-14.5 ps for each run. 


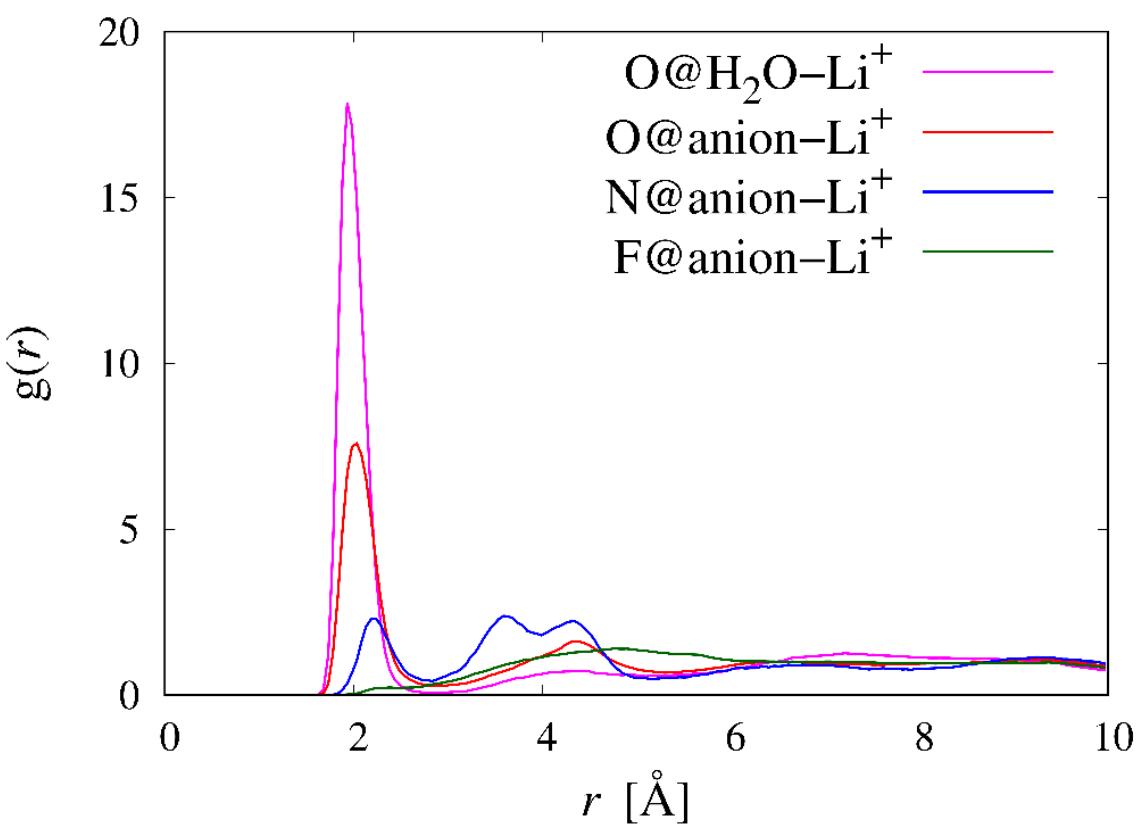

Figure $\mathrm{S} 10$. RDFs from $\mathrm{Li}^{+}$in $\mathrm{LiTFSI}_{0.7} \mathrm{BETI}_{0.3} \cdot 2 \mathrm{H}_{2} \mathrm{O}$ hydrate melt. 